\title{
Pengaruh Sistem Informasi Akuntansi Terhadap Kelebihan Bayar Pajak
}

\author{
Ririn Miptha Nuryana dan Decky Hendarsyah \\ Sekolah Tinggi Ilmu Ekonomi (STIE) Syariah Bengkalis Riau, Indonesia \\ E-Mail: ririnmiftha15@gmail.com, deckydb@gmail.com
}

\section{ABSTRACT}

The awareness of taxpayers in paying taxes is very necessary because development in Indonesia requires very large funds, one source of government funds is revenue from the taxation sector so that state revenue can be met and development can continue. This study aims to complement the shortcomings of existing studies and to analyze the effect of the accounting information system (AIS) on tax overpayment (TOP) at the regional financial and asset management agency (RFAMA) of Bengkalis Regency. This study uses a quantitative descriptive method with primary and secondary data sources. The total population at the office of the RFAMA of Bengkalis Regency was 260 people. The sampling technique used purposive sampling, to obtain a sample of 30 people. Data collection techniques using questionnaires, interviews, documentation and literature study. Data analysis using are simple linear regression method, hypothesis testing and coefficient of determination. The results of this study indicate that the AIS have a significant effect on TOP at the RFAMA of Bengkalis Regency. This study can contribute to the office of the RFAMA of Bengkalis Regency in implementing an AIS and minimizing the occurrence of TOP.

Keywords: accounting information systems, tax overpayment, accounting, taxation.

\section{ABSTRAK}

Kesadaran wajib pajak dalam membayar pajak sangat diperlukan, sebab pembangunan di Indonesia memerlukan dana yang sangat besar, sumber dana pemerintahan salah satu adalah penerimaan dari sektor perpajakan, sehingga pendapatan negara bisa terpenuhi dan pembangunan dapat berlanjut. Studi ini bertujuan untuk melengkapi kekurangan dari studi yang telah ada dan untuk menganalisa pengaruh sistem informasi akuntansi (SIA) terhadap kelebihan bayar pajak (KBP) pada kantor badan pengelolaan keuangan dan aset daerah (BPKAD) Kabupaten Bengkalis. Studi ini menggunakan metode desktriptif kuantitatif dengan sumber data primer dan sekunder. Jumlah populasi pada kantor BPKAD Kabupaten Bengkalis sebanyak 260 orang. Pengambilan sampel menggunakan teknik purposive sampling, sehingga didapat sampel sebanyak 30 orang. Teknik pengumpulan data menggunakan kuesioner, wawancara, dokumentasi dan studi pustaka. Analisis data menggunakan metode regresi linear sederhana, uji hipotesis dan koefisien determinasi. Hasil studi ini menyatakan bahwa SIA berpengaruh signifikan terhadap KBP pada kantor BPKAD Kabupaten Bengkalis. Studi ini dapat memberikan kontribusi pada kantor BPKAD Kabupaten Bengkalis dalam menerapkan SIA dan meminimalisir terjadinya KBP.

Kata Kunci: sistem informasi akuntansi, kelebihan bayar pajak, akuntansi, perpajakan

\section{PENDAHULUAN}

Pembangunan di Indonesia memerlukan dana yang sangat besar, sumber dana pemerintahan salah satu adalah penerimaan dari sektor perpajakan. Pemahaman mengenai arti dan manfaat pajak sangat diperlukan oleh wajib pajak agar dapat
Submitted: DESEMBER 2020

Accepted: MARET 2021

\section{JIAKES}

$$
\begin{array}{r}
\text { Jurnal Ilmiah Akuntansi } \\
\text { Kesatuan } \\
\text { Vol. } 9 \text { No. 1, 2021 } \\
\text { pg. 43-52 } \\
\text { IBI Kesatuan } \\
\text { ISSN } 2337-7852 \\
\text { E-ISSN 2721 - 3048 }
\end{array}
$$


Tax Overpayment and Acconting Information System

meningkatkan kesadaran dalam membayar pajak sehingga pendapatan negara terpenuhi dan pembangunan dapat berlanjut. Tetapi disisi lain terdapat kekhawatiran oleh wajib pajak dalam menunaikan pajak, karena disebabkan terdapatnya kasus-kasus penggelapan pajak oleh oknum aparatur perpajakan. Oleh sebab itu wajib pajak harus paham dengan pajak dan cara menghitungnya, supaya tidak terjadi penyelewengan dan kesalahan dalam membayar pajak (Mangundap \& Tirayoh, 2016). Dalam perpajakan terdapat kejadian dimana nilai pajak yang masuk lebih besar daripada pajak yang keluar, disebut dengan KBP (Lempas, Runtu, \& Pusung, 2017; Mangundap \& Tirayoh, 2016; Riftiasari, 2019). Kegiatan pengembalian KBP disebut dengan restitusi (Mangundap \& Tirayoh, 2016; Usman, 2017). Kebijakan restitusi kepada wajib pajak merupakan suatu dilema, karena dianggap membuka peluang kerugian kas negara (Lempas et al., 2017). Oleh sebab itu agar KBP bisa diminilisir, wajib pajak hendaknya berperan aktif dalam melakukan perhitungan dan pelaporan pajaknya dan pegawai pajak lebih berhati-hati dalam memproses dan menginput data pajak. Dalam melakukan pengelohan KBP dibutuhkan suatu SIA, agar KBP tersistem dan dapat meminimalisir kesalahan dalam perhitungan dan pelaporannya.

Sampai saat ini studi tentang SIA berhubungan dengan beberapa aspek. Pertama, studi yang melihat pengaruh antara SIA dengan aspek efektivitas, studi ini dilakukan oleh (Herawaty \& Sari, 2017; Irton \& Purwanto, 2018; Karmila \& Hendarsyah, 2019; Pebrianti, Faridah, \& Mariantha, 2020; Zulaila \& Hendarsyah, 2020). Kedua, studi yang melihat pengaruh antara SIA dengan aspek kinerja, studi dilakukan oleh (Dita \& Putra, 2016; Irawati \& Ardianshah, 2018; Melasari, 2017; P., Afrizal, \& Wahyudi, 2020; Prastika \& Purnomo, 2014; Purnata \& Suardikha, 2019; Widhawati \& Damayanthi, 2018). Ketiga, studi yang melihat pengaruh antara SIA dengan aspek kualitas, studi ini dilakukan oleh (Darma \& Sagala, 2020; Eveline, 2016; Gusherinsya \& Samukri, 2020; Puteri, Yuliarti, \& Nastiti, 2019; Rohmah, Askandar, \& Sari, 2020; Wulandari \& Hendarsyah, 2020). Keempat, studi yang melihat pengaruh SIA dengan aspek penerimaan, studi ini dilakukan oleh (Angraini \& Hendarsyah, 2019; Tambe, Sunarya, \& Yusuf, 2018). Sedangkan studi yang membahas mengenai KBP, dilakukan oleh (Lempas et al., 2017; Mangundap \& Tirayoh, 2016; Riftiasari, 2019). Melihat dari beberapa aspek tersebut belum banyak studi yang melakukan pembahasan mengenai KBP, apalagi jika dihubungkan dengan SIA.

Studi ini secara khusus membahas mengenai SIA dan KBP yang diterapkan pada kantor BPKAD Kabupaten Bengkalis. Selain itu studi ini bertujuan untuk melengkapi kekurangan dari studi yang telah ada, dimana masih terdapat celah penelitian selain dari aspek-aspek yang telah dijelaskan sebelumnya yaitu jika SIA dihubungkan dengan KBP. Kemudian studi ini juga bertujuan untuk menganalisa dan menggali pengaruh SIA terhadap KBP pada kantor BPKAD Kabupaten Bengkalis. Studi ini didasarkan pada kenyataan di lapangan bahwa SIA dapat mempengaruhi KBP baik dari segi pengembalian maupun pelaporannya, hal tersebut disebabkan terdapatnya komponen dari SIA dalam mempengaruhi KBP. Dengan diterapkannya komponen-komponen SIA tersebut dengan baik maka dapat meminimalisir terjadinya KBP sehingga tidak terjadi kesalahan dan penyelewengan yang dapat merugikan wajib pajak dan negara.

Menurut undang-undang nomor 16 tahun 2009 pasal 1 ayat 1 bahwa pajak merupakan kontribusi wajib kepada negara yang terutang oleh orang pribadi atau badan yang bersifat memaksa berdasarkan undang-undang, dengan tidak mendapatkan jasa timbal balik secara langsung dan digunakan untuk keperluan negara dalam memakmurkan rakyat (Mardiasmo, 2016, p. 3). Dalam memungut pajak terdapat syarat-syarat yang harus terpenuhi yaitu: (a) pemungutan pajak harus adil; (b) pemungutan pajak harus berdasarkan undang-undang; (c) tidak mengganggu perekonomian; (d) pemungutan pajak harus efisien; (e) sistem pemungutan pajak harus sederhana (Mardiasmo, 2016; Usman, 2017).

KBP terjadi apabila terdapat jumlah pajak masukan yang melebihi pajak pengeluaran dan juga terdapatnya kesalahan pemotongan atau pemungutan yang berupa besarnya potongan yang seharusnya tidak dipotong (Lempas et al., 2017; Mangundap \& Tirayoh, 
2016; Riftiasari, 2019; Usman, 2017). Restitusi merupakan pengembalian KBP terjadi karena jumlah pajak masukan yang dibayar lebih besar daripada jumlah pajak keluaran yang dipungut dalam suatu masa pajak (Mangundap \& Tirayoh, 2016; Usman, 2017).

Restitusi dapat dilakukan dengan prosedur sebagai berikut: (a) wajib pajak mengajukan permohonan restitusi ke kantor pelayanan pajak; (b) kantor pelayanan pajak memeriksa dan menerbitkan surat ketetapan pajak lebih bayar (SKPLB) oleh dewan jenderal pajak (DJP); (c) SKPLB diterbitkan paling lambat 12 bulan sejak surat permohonan diterima secara lengkap, kecuali untuk kegiatan tertentu ditetapkan lain dengan keputusan DJP; (d) Apabila dalam jangka waktu 12 bulan sejak permohonan restitusi, DJP tidak memberikan keputusan, maka permohonan dianggap dikabulkan, dan SKPLB diterbitkan dalam jangka waktu paling lambat 1 bulan setelah jangka waktu berakhir (Riftiasari, 2019). Dalam KBP terdapat kompensasi dimana pajak tahun sebelumnya terdapat kelebihan bayar maka kelebihan tersebut dapat digunakan sebagai utang pajak tahun berikutnya atau KBP tertentu dikompensasikan dengan utang pajak lain pada tahun yang sama (Lempas et al., 2017). Sistem merupakan rangkaian komponen yang dikoordinasikan untuk mencapai serangkaian tujuan (Krismiaji, 2010, p. 1). Informasi adalah data yang telah diorganisasi dan telah memiliki kegunaan dan manfaat (Krismiaji, 2010, p. 15). SIA merupakan sebuah sistem yang mengumpulkan, mencatat, menyimpan serta memproses data menjadi informasi yang berguna dalam membantu proses pengambilan keputusan agar sesuai dengan tujuan perusahaan (Romney \& Steinbart, 2015, p. 36).

SIA mempunyai tujuan untuk: (a) mengamankan aset perusahaan; (b) menghasilkan informasi untuk pihak internal dalam mengambil keputusan; (c) menghasilkan informasi untuk pihak eksternal; (d) menghasilkan informasi untuk penilaian kinerja pegawai atau organisasi; (e) menyediakan data masa lalu untuk kepentingan audit; (f) menghasilkan informasi untuk penyusunan dan evaluasi anggaran perusahaan; (g) menghasilkan informasi untuk kegiatan perencanaan dan pengendalian (Putri \& Endiana, 2020). SIA memiliki komponen yang terdiri dari: (a) sumber daya manusia; (b) prosedur dan instruksi; (c) data; (d) perangkat lunak; (e) infrastruktur teknologi informasi atau perangkat keras; (f) pengendalian internal dan pengukuran keamanan (Romney \& Steinbart, 2015).

Studi yang menyatakan bahwa SIA berpengaruh terhadap efektivitas dikemukan oleh (Herawaty \& Sari, 2017; Irton \& Purwanto, 2018; Karmila \& Hendarsyah, 2019; Pebrianti et al., 2020; Zulaila \& Hendarsyah, 2020), dimana efektivitas berdasarkan variabel dependent masing-masing studi. Kemudian studi yang menyatakan bahwa SIA berpengaruh terhadap kinerja baik individual maupun organisasi dikemukakan oleh (Dita \& Putra, 2016; Endiana \& Sudiartana, 2016; Irawati \& Ardianshah, 2018; Jayantara \& Dharmadiaksa, 2016; Melasari, 2017; Nengsy, 2018; P. et al., 2020; Pawitri \& Latrini, 2019; Prastika \& Purnomo, 2014; Purnata \& Suardikha, 2019; Suryawan \& Suaryana, 2018; Widhawati \& Damayanthi, 2018; D. M. A. P. Wiguna \& Dharmadiaksa, 2016; P. A. H. Wiguna, Wahyuni, \& Atmadja, 2016), sedangkan studi yang menyatakan bahwa SIA tidak berpengaruh terhadap kinerja baik individual maupun organisasi dikemukan oleh (Amiruddin, Dhanny, \& Rafika, 2019; Lukiman \& Lestarianto, 2016; Ningsih \& Natalia, 2020; Putri \& Endiana, 2020; Wahyuni, Marsdenia, \& Soenarto, 2016). Selanjutnya studi yang menyatakan bahwa SIA berpengaruh terhadap kualitas dikemukan oleh (Darma \& Sagala, 2020; Eveline, 2016; Gusherinsya \& Samukri, 2020; Puteri et al., 2019; Rohmah et al., 2020; Wulandari \& Hendarsyah, 2020), dimana kualitas berdasarkan variabel dependent masing-masing studi. Kemudian studi yang menyatakan bahwa SIA berpengaruh terhadap pencatatan penerimaan negara bukan pajak dikemukan oleh (Angraini \& Hendarsyah, 2019), sedangkan studi yang menyatakan bahwa SIA tidak berpengaruh terhadap penerimaan pajak kendaraan bermotor dikemukan oleh (Tambe et al., 2018). Dari hasil studi mengenai SIA tersebut, mayoritas menyatakan bahwa SIA sebagai variabel independent berpengaruh terhadap variabel dependent masing-masing studi, maka dari itu dapat dibentuk hipotesis yaitu: SIA berpengaruh signifikan terhadap KBP pada kantor BPKAD Kabupaten Bengkalis.
Tax Overpayment and Accounting Information System 
Tax Overpayment

and Acconting

Information System

\section{METODE PENELITIAN}

Studi ini dilaksanakan pada BPKAD Kabupaten Bengkalis Provinsi Riau, dimana populasinya berjumlah 260 orang. Studi ini menggunakan metode desktriptif kuantitatif dengan sumber data primer dan sekunder. Dalam pengambilan sampel teknik yang digunakan adalah purposive sampling dimana teknik ini bertujuan untuk memilih sampel berdasarkan karakteristik tertentu yang dianggap memiliki sangkut paut dengan pegawai yang mengoperasikan SIA yang bernama surat setoran elektronik (SSE), sehingga didapat sampel sebanyak 30 orang, terdiri dari 1 orang bendahara, 1 orang wakil bendahara dan 28 orang staf keuangan. Teknik pengumpulan data pada studi ini menggunakan kuesioner, dokumentasi dan studi pustaka. Analisis data menggunakan regresi linear sederhana, uji hipotesis dan koefisien determinasi dengan menggunakan alat bantu berupa perangkat lunak SPSS.

\section{HASIL DAN PEMBAHASAN \\ Penerapan SIA}

Sejak awal berdirinya kantor BPKAD Kabupaten Bengkalis pada tahun 2017 sudah menggunakan sistem informasi berbasis online, dengan menggunakan perangkat lunak SSE. Saat pertama kali instansi ini menggunakan SSE versi 1, kemudian di update menjadi versi 2 dan terakhir beralih ke versi 3 karena terdapat pembaruan yang lebih lengkap dan akurat. Menurut hasil wawancara dengan bendahara BPKAD Bengkalis bahwa terdapat kelebihan setelah menggunakan SIA yaitu secara umum informasi yang disajikan lebih akurat dan tidak memakan waktu yang lama. Sedangkan kekurangan sebelum menggunakan SIA data yang disajikan kurang akurat dan memakan waktu yang lama dalam pengerjaanya.

\section{Data Responden}

Kuesioner yang telah diserahkan kepada pegawai BPKAD Kabupaten Bengkalis semua dikembalikan, sehingga didapat data responden berjumlah 30 orang. Setelah data responden diolah, maka data dapat dikategorikan berdasarkan jenis kelamin, umur dan tingkat pendidikan. Berdasarkan kategori jenis kelamin didapat jumlah laki-laki sebanyak 13 orang $(43,33 \%)$ dan perempuan sebanyak 17 orang $(56,67 \%)$. Berdasarkan kategori umur, rentang umur 26 sampai 30 tahun sebanyak 5 orang $(16,67 \%)$, rentang umur 31 sampai 35 tahun sebanyak 10 orang $(33,33 \%)$, rentang umur 36 sampai 50 tahun sebanyak 8 orang $(26,67 \%)$ dan rentang umur diatas 50 tahun sebanyak 7 orang $(23,33 \%)$. Berdasarkan kategori tingkat pendidikan, Diploma 3 sebanyak 4 orang $(13,33 \%)$, S1 sebanyak 16 orang $(53,34 \%)$, S2 sebanyak 9 orang $(30 \%)$ dan S3 sebanyak 1 orang $(3,33 \%)$.

\section{Validitas}

Berdasarkan hasil kuesionar dapat diketahui bahwa nilai $\alpha=0,05 ; \mathrm{n}=30 ; \mathrm{df}=\mathrm{n}-2$ $=30-2=28$, sehingga $r_{\text {tabel }}$ dapat dicari dengan menggunakan tabel $r$ dengan hasil sebesar 0,361 . Dalam menentukan validitas data diperlukan syarat pengambilan keputusan dalam menyatakan suatu data valid atau tidak. Data dikatakan valid syaratnya apabila $\mathrm{r}_{\text {hitung }}>\mathrm{r}_{\text {tabel, }}$, selain itu data tidak valid (Siregar, 2013, p. 47). Dari hasil olahan data kuesioner didapat rentang nilai $r_{\text {hitung. }}$. Dimana nilai $r_{\text {hitung }}$ terendah sebesar 0,471 dan $r_{\text {hitung }}$ tertinggi sebesar 0,804 . Sehingga data kuesioner dapat dikatakan valid, karena nilai seluruh $\mathrm{r}_{\text {hitung }}>\mathrm{r}_{\text {tabel }}$.

\section{Reliabilitas}

Dalam melakukan pengujian reliabilitas dapat dilakukan dengan cara menguji semua hasil pertanyaan kuesioner, dimana kriteria hasil pengujian dikatakan reliabel apabila nilai cronbach's alpha $>0,60$ (Siregar, 2013, p. 57). Dari hasil olahan data kuesioner didapat nilai cronbach's alpha sebesar 0,889, dimana nilai tersebut lebih besar dari 0,60, sehingga dapat dikatakan bahwa data kuesioner secara keseluruhan reliabel.

\section{Normalitas}

Normalitas bertujuan untuk mengetahui apakah variabel yang diuji berdistribusi normal atau tidak. Pengujian dapat dilakukan menggunakan metode Kolmogrov-Smirnov 
Test dan analisis grafik normal P-Plot. Dalam mengambil keputusan data berdistribusi normal apabila nilai signifikan $>0,05$ dan titik pada grafik $P$-Plot menyebar disekitar garis dan mengikuti garis diagonal (Siregar, 2013, p. 243). Dari hasil pengujian KolmogrovSmirnov didapat nilai signifikan sebesar 0,415 , artinya $0,415>0,05$. Kemudian pada Gambar 1 dapat dilihat bahwa titik menyebar disekitar garis dan mengikuti garis diagonal, sehingga dapat dikatakan bahwa data berdistribusi normal.

\section{Dependent Variable: y}

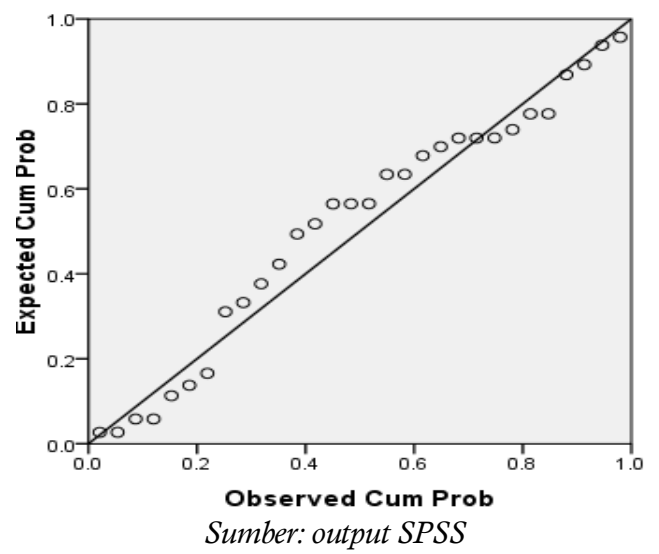

Gambar 1. Normal P-Plot
Tax Overpayment and Accounting Information System

\section{Regresi Liner Sederhana}

Berdasarkan Tabel 1 dapat dibentuk persamaan regresi antara variabel SIA dengan KBP yaitu: $\mathrm{Y}=\alpha+\beta \mathrm{X} ; \mathrm{Y}=0,026+0,417 \mathrm{X}$, sehingga dapat dijabarkan bahwa nilai $\alpha$ merupakan nilai konstan sebesar 0,026 yang berarti apabila variabel SIA bernilai nol maka didapat nilai KBP sebesar 0,026 . Nilai $\beta$ merupakan koefisien dari variabel SIA dengna nilai sebesar 0,417 yang berarti setiap penambahan 1 satuan variabel SIA maka nilai variabel $\mathrm{KBP}$ akan bertambah sebesar 0,417 . Berhubung koefisien bernilai positif artinya terjadi hubungan positif antara SIA dengan KBP.

Tabel 1. Coefficients dan Model Summary

\begin{tabular}{lccc}
\hline \multicolumn{1}{c}{ Model } & $\boldsymbol{\alpha} / \boldsymbol{\beta}$ & $\boldsymbol{t}$ & Sig. \\
\hline (Constant) & 0,026 & 0,012 & 0,990 \\
SIA & 0,417 & 9,783 & 0,000 \\
\hline$R$ & 0,880 & & \\
Adjusted $R$ Square & 0,766 & & \\
\hline Sumber: olahan output SPSS & & &
\end{tabular}

\section{Uji Hipotesis}

Hipotesis diuji menggunakan uji $t$, dimana pengujian ini bertujuan untuk menunjukkan pengaruh variabel dependent dengan variabel independent secara individual sehingga didapat nilai $t_{\text {hitung, }}$ kemudian dibandingkan dengan $t_{\text {tabel. }}$. Untuk mencari nilai $t_{\text {tabel }}$ diperlukan nilai $\alpha$ dan df, dimana $\alpha=\alpha / 2=0,05 / 2=0.025 ; \mathrm{df}=\mathrm{n}-\mathrm{k}=30-2=28$, sehingga didapat nilai $t_{\text {tabel }}$ sebesar 2,048. Keputusan hipotesis diterima apabila nilai $t_{\text {hitung }}$ $>t_{\text {tabel }}$ atau nilai sig. $<0,05$ selain itu keputusan hipotesis ditolak (Yusuf, 2014, p. 244). Pada Tabel 1 dapat dilihat bahwa pada varibael SIA nilai $t_{\text {hitung }}$ sebesar 9,783 dan nilai sig. sebesar 0,000 , yang artinya nilai $t_{\text {hitung }}>t_{\text {tabel }}(9,783>2,048)$ dan nilai sig. $<0,05(0,000<$ $0,05)$, sehingga hipotesis diterima.

\section{Koefisien Diterminasi}

Hasil koefisien determinasi dapat dilihat pada Tabel 2, dimana terdapat nilai korelasi (R) sebesar 0,880, yang berarti bahwa terdapat hubungan yang sangat kuat antara SIA dengan KBP, karena nilai korelasi lebih besar dari 0,8 (Sugiyono, 2014). Kemudian nilai Adjusted $R$ Square sebesar 0,766, ini artinya SIA mempunyai pengaruh terhadap KBP yaitu sebesar 0,766 atau sama dengan $76,6 \%$.

\section{Pengaruh SIA Terhadap KBP}

Hasil studi menyatakan bahwa hipotesis diterima, ini berarti bahwa SIA berpengaruh signifikan terhadap KBP pada kantor BPKAD Kabupaten Bengkalis. Hal tersebut 
Tax Overpayment and Acconting Information System menunjukkan bahwa penerapan SIA merupakan aspek yang sangat penting dalam pengelolaan pajak. Mulai dari mengumpulkan data pajak, menginput dan memproses data sampai menghasilkan informasi berupa laporan. Ketika mengumpulkan data harus diperhatikan tingkat kebenaran data yang diberikan wajib pajak, kemudian menginput data harus berhati-hati dan tidak boleh salah, sehingga informasi atau laporan yang dihasilkan valid.

Dari segi komponen SIA, ini sangat berpengaruh terhadap pengelolaan dan pelaporan KPB, karena semua komponen SIA saling berkaitan. Mulai dari segi sumber daya manusia, BPKAD Kabupaten Bengkalis telah menyiapkan pegawai yang mumpuni. Dari segi prosedur telah dilaksanakan dengan tertib. Dari segi data, sudah melalui validasi, akurasi dan kelengkapan. Dari segi perangkat lunak sudah tersedia aplikasi SSE. Dari segi infrastuktur teknologi informasi baik berupa perangkat keras, jaringan lokal dan internet sudah tersedia dan dapat mendukung pekerjaan. Dari segi pengendalian internal sudah memenuhi standar, tetapi perlu dikaji lebih dalam. Akan tetapi dari semua komponen SIA yang lebih besar pengaruhnya adalah komponen sumber daya manusia atau pegawai, karena mulai dari mengumpulkan data, sampai pembuatan laporan dikerjakan oleh pegawai. Jika terjadi kesalahan dalam perhitungan dan input data, ini akan mengakibatkan semakin besar KBP. Jika pegawai melakukan keterlambatan dalam memproses dan membuat laporan pajak, ini akan mengakibatkan wajib pajak menjadi kesulitan dalam mengklaim KBP. Jika ada pegawai yang melakukan penyelewengan diarea ini maka akan menimbulkan kerugian. Oleh sebab itu semakin baik penerapan SIA maka KBP dapat diminimalisir, sebaliknya jika penerapan SIA tidak diterapkan dengan baik maka KBP akan semakin besar, ini akan mengakibatkan bertambahnya pekerjaan dalam menerbitkan SKPLB, membuat wajib pajak sulit dalam mengklaim KBP, sehingga akhirnya dapat memicu kerugian terhadap wajib pajak dan negara. Penerapan SIA pada BPKAD Kabupaten Bengkalis telah mampu memberikan informasi yang tepat sesuai dengan kebutuhan wajib pajak. Hal ini terlihat dari tersedianya informasi yang dibutuhkan akurat, relevan dan tepat waktu sebagai penunjang dalam melakukan pekerjaan di instansi ini. Kemudian BPKAD Kabupaten Bengkalis telah meminimalisir terjadinya KBP dengan mengadakan pelatihan SIA dalam penggunaan perangkat lunak SSE dan mengikuti seluruh peraturan dan prosedur yang telah ditetapkan.

Hasil studi ini sejalan dengan studi yang telah dilakukan oleh (Angraini \& Hendarsyah, 2019; Darma \& Sagala, 2020; Dita \& Putra, 2016; Endiana \& Sudiartana, 2016; Eveline, 2016; Gusherinsya \& Samukri, 2020; Herawaty \& Sari, 2017; Irawati \& Ardianshah, 2018; Irton \& Purwanto, 2018; Jayantara \& Dharmadiaksa, 2016; Karmila \& Hendarsyah, 2019; Melasari, 2017; Nengsy, 2018; P. et al., 2020; Pawitri \& Latrini, 2019; Pebrianti et al., 2020; Prastika \& Purnomo, 2014; Purnata \& Suardikha, 2019; Puteri et al., 2019; Rohmah et al., 2020; Suryawan \& Suaryana, 2018; Widhawati \& Damayanthi, 2018; D. M. A. P. Wiguna \& Dharmadiaksa, 2016; P. A. H. Wiguna et al., 2016; Wulandari \& Hendarsyah, 2020; Zulaila \& Hendarsyah, 2020) yang menyatakan bahwa SIA berpengaruh terhadap variabel dependent pada studi mereka masing-masing, dimana SIA dilihat sebagai variabel independent, Hasil studi ini tidak sejalan dengan studi yang telah dilakukan oleh (Amiruddin et al., 2019; Lukiman \& Lestarianto, 2016; Ningsih \& Natalia, 2020; Putri \& Endiana, 2020; Tambe et al., 2018; Wahyuni et al., 2016) yang menyatakan bahwa SIA tidak berpengaruh terhadap variabel dependent pada studi mereka masing-masing, dimana SIA dilihat sebagai variabel independent.

\section{PENUTUP}

Ternyata SIA jika dihubungkan dengan KBP merupakan suatu hal yang baru dan belum ditemukan studi tentang hal tersebut sehingga studi ini dapat menambah kekurangan studi yang telah ada. Dilihat dari segi korelasi, terjadi hubungan yang sangat kuat antara SIA dengan KBP pada kantor BPKAD Kabupaten Bengkalis. Hal tersebut terbukti dengan terdapatnya pengaruh yang signifikan antara SIA dengan KBP pada kantor BPKAD Kabupaten Bengkalis dengan besar pengaruh 76,6\%. Dengan adanya penerapan SIA yang baik, BPKAD Kabupaten Bengkalis mampu memberikan informasi 
yang tepat sesuai dengan kebutuhan wajib pajak. Studi ini dapat memberikan kontribusi pada kantor BPKAD Kabupaten Bengkalis dalam menerapkan SIA dan meminimalisir terjadinya KBP.

Studi ini mempunyai keterbatasan baik dari segi waktu maupun ruang lingkup studi, untuk itu diharapkan ada studi lanjutan terhadap KBP selain faktor SIA, seperti pengetahuan wajib pajak, sistem pengendalian internal dan faktor-faktor lainnya yang dapat mempengaruhi KBP, karena masih terbuka ruang studi sebesar 23,4\%. Diharapkan pada kantor BPKAD Kabupaten Bengkalis dapat selalu mengupdate kemampuan sumber daya manusia dalam menggunakan SIA dengan cara mengadakan pelatihan-pelatihan dalam mengelola SIA. Kemudian diharapkan pada kantor BPKAD untuk rutin melakukan sosialisasi tentang perhitungan dan pelaporan pajak serta pemahaman arti pentingnya pajak kepada wajib pajak. Selanjutnya diharapkan pada kantor BPKAD Kabupaten Bengkalis agar dapat menjaga konsistensi penerapan SIA sehingga dapat meminimalisir KBP dan mencegah kerugian terhadap wajib pajak dan negara.

\section{DAFTAR PUSTAKA}

Amiruddin, A., Dhanny, O., \& Rafika, R. (2019). Pengaruh Sistem Informasi Akuntansi Berbasis Komputer Dan Sistem Pengendalian Internal Terhadap Kinerja Instansi Pemerintah Kota Samarinda (Studi Satuan Kerja Perangkat Daerah Kota Samarinda). Jurnal Eksis, 15(1), 53-67. Retrieved from http://ejournal.polnes.ac.id/index.php/eksis/article/view/262

Angraini, D., \& Hendarsyah, D. (2019). Pengaruh Sistem Informasi Akuntansi (Komputerisasi Kegiatan Pertanahan) Terhadap Pencatatan Penerimaan Negara Bukan Pajak Pada Kantor Pertanahan Kabupaten Bengkalis. JAS (Jurnal Akuntansi Syariah), 3(1), 20-36. https://doi.org/10.46367/jas.v3i1.160

Darma, J., \& Sagala, G. H. (2020). Pengaruh Kualitas Sistem Informasi Akuntansi Terhadap Kualitas Informasi Akuntansi (Studi Emptiris di Indonesia). Jurnal Ilmiah MEA (Manajemen, Ekonomi \& Akuntansi), 4(1), 227-237. Retrieved from http://journal.stiemb.ac.id/index.php/mea/article/view/231

Dita, M. A., \& Putra, I. W. (2016). Pengaruh Penerapan Sistem Informasi Akuntansi Terhadap Kinerja Karyawan Dengan Integritas Karyawan Sebagai Variabel Pemoderasi. E-Jurnal Akuntansi, 15(1), 614-640. Retrieved from https://ocs.unud.ac.id/index.php/Akuntansi/article/view/17695

Endiana, I. D. M., \& Sudiartana, I. M. (2016). Pengaruh Pemahaman dan Penerapan Sistem Informasi Akuntansi Terhadap Kinerja Individu dan Kinerja UMKM Pengrajin Perak. JUARA: Jurnal Riset Akuntansi, 6(4), 96-104. Retrieved from http://jurnal.unmas.ac.id/index.php/JUARA/article/view/567

Eveline, F. (2016). Pengaruh SAP Berbasis Akrual, Sistem Informasi Akuntansi, Kualitas SDM, Pengendalian Internal dan Komitmen Organisasi terhadap Kualitas Laporan Keuangan di Badan Nasional Penanggulangan Bencana. Media Riset Akuntansi, Auditing \& Informasi, 16(1), 1-14. https://doi.org/10.25105/mraai.v16i1.2004

Gusherinsya, R., \& Samukri, S. (2020). Pengaruh Penerapan Sistem Informasi Akuntansi Terhadap Kualitas Laporan Keuangan. Jurnal Akuntansi, 9(1), 58-68. https://doi.org/10.37932/ja.v9i1.94

Herawaty, N., \& Sari, R. Y. (2017). Pengaruh Sistem Informasi Akuntansi Terhadap Efektivitas Penjualan Dengan Pengendalian Intern Sebagai Variabel Intervening (Survei Pada Kerajinan Batik Di Kota Jambi). Jurnal Akuntansi (Media Riset Akuntansi \& Keuangan), 6(2), 131-142. Retrieved from https://ja.ejournal.unri.ac.id/index.php/JA/article/view/5265

Irawati, A., \& Ardianshah, R. (2018). Pengaruh Karakteristik Sistem Informasi Akuntansi Manajemen Terhadap Kinerja Manajerial Dengan Desentralisasi Sebagai Variabel Moderating. Jurnal Akuntansi \& Keuangan, 9(1), 34-53. https://doi.org/10.36448/jak.v9i1.997
Tax Overpayment and Accounting Information System 
Tax Overpayment and Acconting Information System
Irton, I., \& Purwanto, M. I. (2018). Dampak Penggunaan Sistem Informasi Akuntansi terhadap Efektivitas Pengendalian Internal Lembaga Keuangan Mikro Syariah. At-Tauzi: Islamic Economic Journal, 18(1), 18-26. Retrieved from http://jurnalhamfara.ac.id/index.php/attauzi/article/view/15

Jayantara, I. K., \& Dharmadiaksa, I. B. (2016). Pengaruh Kemampuan Teknik Pemakai Dan Efektivitas Sistem Informasi Akuntansi (SIA) Terhadap Kinerja Individual. E-Jurnal Akuntansi Universitas Udayana, 17(3), 2145-2170. Retrieved from https://ojs.unud.ac.id/index.php/Akuntansi/article/view/22412

Karmila, K., \& Hendarsyah, D. (2019). Pengaruh Sistem Informasi Akuntansi Retribusi Boarding Pass Pelabuhan Terhadap Sistem Pengendalian Internal: Studi Pada PT. Pelabuhan Indonesia I (Persero) Cabang Dumai. JAS (Jurnal Akuntansi Syariah), 3(2), 158-173. https://doi.org/10.46367/jas.v3i2.180

Krismiaji. (2010). Sistem Informasi Akuntansi. Yogyakarta: Sekolah Tinggi Ilmu Manajemen YKPN.

Lempas, B. S., Runtu, T., \& Pusung, R. J. (2017). Analisis Sistem Kebijakan Pengembalian Kelebihan Pembayaran Wajib Pajak Orang Pribadi Melalui Restitusi Dan Kompesansi Di KPP Pratama Manado. Going Concern: Jurnal Riset Akuntansi, 12(2), 694-702. https://doi.org/10.32400/gc.12.2.18032.2017

Lukiman, R., \& Lestarianto, J. B. W. (2016). Pengaruh Penerapan Sistem Informasi Akuntansi, Pemanfaatan Sistem Informasi, Efektivitas Penggunaan Sistem Informasi Akuntansi, Kepercayaan Atas Teknologi Sistem Informasi Akuntansi, Dan Teknologi Informasi Terhadap Kinerja Individu Karyawan. ULLTIMA Accounting: Jurnal Ilmu Akuntansi, 8(2), 46-65. https://doi.org/10.31937/akuntansi.v8i2.581

Mangundap, P. V., \& Tirayoh, V. Z. (2016). Analisis Prosedur Restitusi Kelebihan Pembarayan Pajak Pertambahan Nilai (PPN) Pada Kantor Pelayanan Pajak Pratama Manado. Jurnal EMBA: Jurnal Riset Ekonomi, Manajemen, Bisnis Dan Akuntansi, 4(1), 98-108. Retrieved from https://ejournal.unsrat.ac.id/index.php/emba/article/view/11566

Mardiasmo. (2016). Perpajakan. Yogyakarta: Andi Offset.

Melasari, R. (2017). Pengaruh Sistem Informasi Akuntansi Terhadap Kinerja Karyawan Dengan Integritas Karyawan Sebagai Variabel Pemoderasi Pada Perbankan Di Tembilahan. Jurnal Akuntansi Dan Keuangan, 6(1), 1-15. Retrieved from https://ejournal.unisi.ac.id/index.php/jak/article/view/254

Nengsy, H. (2018). Pengaruh Sistem Informasi Akuntansi dan Penggunaan Teknologi Informasi Akuntansi Terhadap Kinerja Manajerial pada Perbankan di Tembilahan. Jurnal Akuntansi Dan Keuangan, 7(1), 1-17. Retrieved from https://ejournal.unisi.ac.id/index.php/jak/article/view/244

Ningsih, Y., \& Natalia, E. Y. (2020). Pengaruh Sistem Informasi Akuntansi Dan Motivasi Kerja Terhadap Kinerja Karyawan Pada PT Wook Global Technology. Jurnal EMBA: Jurnal Riset Ekonomi, Manajemen, Bisnis Dan Akuntansi, 8(1), 935944.

Retrieved

from https://ejournal.unsrat.ac.id/index.php/emba/article/view/28043

P., A. D., Afrizal, A., \& Wahyudi, I. (2020). Pengaruh Efisiensi Kerja, Efektifitas Sistem Informasi Akuntansi, Penggunaan Teknologi Informasi dan Kepuasan Pengguna Sistem Informasi Akuntansi Terhadap Kinerja Individual di PT. POS Indonesia (Persero) Kantor Pos Jambi. Jurnal Akuntansi \& Keuangan Unja, 5(3), 192-202. Retrieved from https://online-journal.unja.ac.id/jaku/article/view/10810

Pawitri, N. M. S., \& Latrini, M. Y. (2019). Pengaruh Efektivitas Penggunaan SIA, Pelatihan SIA, dan LOC Internal Pada Kinerja Karyawan LPD Kota Denpasar. E-Jurnal Akuntansi, 27(3), 2100-2128. https://doi.org/10.24843/EJA.2019.v27.i03.p17

Pebrianti, S. L., Faridah, F., \& Mariantha, I. N. (2020). Pengaruh Sistem Informasi Akuntansi Terhadap Efektivitas Pengendalian Internal Pada PT Bosowa Berlian 
Motor Makassar. Economics Bosowa Journal, 6(002), 56-66. Retrieved from http://economicsbosowa.unibos.id/index.php/eb/article/view/331

Prastika, N. E., \& Purnomo, D. E. (2014). Pengaruh Sistem Informasi Akuntansi terhadap Kinerja Perusahaan pada Usaha Mikro Kecil dan Menengah (UMKM) di Kota Pekalongan. Jurnal LITBANG Kota Pekalongan, 7. Retrieved from https://jurnal.pekalongankota.go.id/index.php/litbang/article/view/86

Purnata, I. W. R., \& Suardikha, I. M. S. (2019). Pengaruh E-Commerce, Budaya Organisasi, dan Penggunaan Sistem Informasi Akuntansi terhadap Kinerja Keuangan Perusahaan pada UKM. E-Jurnal Akuntansi, 28(1), 296-321. https://doi.org/10.24843/EJA.2019.v28.i01.p12

Puteri, I. P., Yuliarti, N. C., \& Nastiti, A. S. (2019). Pengaruh Pemahaman Akuntansi Dan Pemanfaatan Sistem Informasi Akuntansi Terhadap Kualitas Laporan Keungan (Studi Kasus Pada Bni Cabang Situbondo). Jurnal Akuntansi Profesi, 10(2), 150-158. Retrieved from https://ejournal.undiksha.ac.id/index.php/JAP/article/view/23071

Putri, P. A. Y., \& Endiana, I. D. M. (2020). Pengaruh Sistem Informasi Akuntansi Dan Sistem Pengendalian Internal Terhadap Kinerja Perusahaan (Studi Kasus Pada Koperasi Di Kecamatan Payangan). KRISNA: Kumpulan Riset Akuntansi, 11(2), 179-189. https://doi.org/10.22225/kr.11.2.1433.179-189

Riftiasari, D. (2019). Pengaruh Restitusi Kelebihan Pembayaran Pajak Pertambahan Nilai Pada Kantor Pelayanan Pajak Pratama Jakarta Penjaringan. Moneter-Jurnal Akuntansi Dan Keuangan, 6(1), 63-68. https://doi.org/10.31294/moneter.v6i1.5353

Rohmah, L., Askandar, N. S., \& Sari, A. F. K. (2020). Pengaruh Pemahaman Standar Akuntansi Pemerintah, Pemanfaatan Sistem Informasi Akuntansi Keuangan Daerah Dan Sistem Pengendalian Internal Terhadap Kualitas Laporan Keuangan Pemerintah Daerah Kota Malang. Jurnal Ilmiah Riset Akuntansi, 9(05), 43-51. Retrieved http://www.riset.unisma.ac.id/index.php/jra/article/view/8286

Romney, M. B., \& Steinbart, P. J. (2015). Sistem Informasi Akuntansi. Jakarta: Salemba Empat.

Siregar, S. (2013). Metodologi Penelitian Kuantitatif. Jakarta: Kencana.

Sugiyono. (2014). Metode Penelitian Kuantitatif Kualitatif dan R\&D. Bandung: Alfabeta.

Suryawan, K. I., \& Suaryana, I. G. N. A. (2018). Pengaruh Efektivitas Sistem Informasi Akuntansi Terhadap Kinerja Individual Dengan Insentif Sebagai Variabel Pemoderasi Pada LPD. E-Jurnal Akuntansi, 23(2), 871-897. https://doi.org/10.24843/EJA.2018.v23.i02.p03

Tambe, S. R., Sunarya, H., \& Yusuf, A. (2018). Pengaruh Sistem Informasi Akuntansi Terhadap Penerimaan Pajak Kendaraan Bermotor Di kantor Samsat Dan Dinas Pendapatan Daerah Kalabahi Kabupaten Alor. Jurnal Akuntansi Universitas Muhammadiyah Kupang, 5(02), 60-78. Retrieved from https://ejournal.unmuhkupang.ac.id/index.php/ja/article/view/77

Usman, S. W. (2017). Restitusi Dan Proses Managerial Pemeriksaan Restitusi Pajak Pertambahan Nilai Di KPPN Manokwari. Jurnal Nusantara Aplikasi Manajemen Bisnis, 2(1), 57-67. https://doi.org/10.29407/nusamba.v2i1.608

Wahyuni, T., Marsdenia, M., \& Soenarto, I. (2016). Analisis Pengaruh Penerapan Sistem Informasi Akuntansi Terhadap Pengukuran Kinerja UMKM di Wilayah Depok. Jurnal Vokasi Indonesia, 4(2), 28-47. https://doi.org/10.7454/jvi.v4i2.97

Widhawati, A., \& Damayanthi, I. G. A. E. (2018). Pengaruh Efektivitas Penggunaan Sistem Informasi Akuntansi, Budaya Kerja, dan Insentif terhadap Kinerja Karyawan. E-Jurnal Akuntansi, 24(2), 1301-1327. https://doi.org/10.24843/EJA.2018.v24.i02.p18

Wiguna, D. M. A. P., \& Dharmadiaksa, I. B. (2016). Pengaruh Penerapan Sistem Informasi Akuntansi Terhadap Kinerja Individual Dengan Budaya Organisasi
Tax Overpayment and Accounting Information System

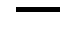


Tax Overpayment and Acconting Information System

Yusuf, M. (2014). Metodologi Penelitian Kuantitatif, Kualitatif \& Penelitian Gabungan. Jakarta: Kencana.

Zulaila, Z., \& Hendarsyah, D. (2020). Pengaruh Penerapan Sistem Informasi Akuntansi Dan Pengetahuan Pengguna Terhadap Efektivitas SISMIOP Pada Badan Pendapatan Daerah Kabupaten Bengkalis. Jurnal IAKP: Jurnal Inovasi Akuntansi Keuangan \& Perpajakan, 1(1), 20-27. Retrieved from http://ejournal.polbeng.ac.id/index.php/iakp/article/view/1408 